\title{
Remodelação estética do sorriso com resina composta e clareamento dental em paciente jovem: relato de caso
}

\author{
Esthetic remodeling of the smile with composite resin and \\ dental bleaching in a young patient: a case report \\ Remodelación estética de la sonrisa con resina compuesta y \\ blanqueamiento dental en paciente joven: reporte de un caso \\ Frederico dos Reis GOYATÁ \\ Hoany Vieira COSTA \\ Luís Henrique Garcia MARQUES \\ Ivan Doche BARREIROS \\ Célia Regina Moreira LANZA \\ João Batista NOVAES JÚNIOR \\ Amália MORENO \\ Departamento de Clínica, Patologia e Cirurgias Odontológicas \\ Faculdade de Odontologia da Universidade Federal de Minas Gerais (FO-UFMG) 31.270-010 Belo Horizonte-MG, Brasil
}

\begin{abstract}
Resumo
A valorização dos aspectos que regem os conceitos de estética na sociedade tornou cada vez mais comum a procura por tratamentos estéticos funcionais. O clareamento dental associado às restaurações diretas são alternativas eficazes para devolver estética e função em tempo clínico curto associado ao baixo custo. Este caso clínico tem por objetivo apresentar a remodelação estética e o fechamento de diastema em região anterior de paciente adulto jovem, com a associação das técnicas de clareamento dental e remodelação/restauração com resina composta. A metodologia clínica desenvolvida neste caso foi eficaz em restabelecer a função e estética aos dentes anteriores da paciente de forma a promover um sorriso mais harmônico.
\end{abstract}

Descritores: Resinas Compostas; Estética Dentária; Dentística Operatória; Clareamento Dental.

\begin{abstract}
Appreciation of the aspects governing the concepts of esthetics in today's society has made it increasingly common to search for functional esthetic treatments. Dental bleaching associated with direct restorations is an effective alternative to restoring esthetics and function in a short clinical time and with a lower cost. This clinical case presents the esthetic remodeling and diastema closure in the anterior region of an young adult patient, with the association of dental whitening techniques and remodeling/restoration using composite resin. The clinical method developed in this case was effective in restoring function and esthetics to the patient's anterior teeth in order to promote a more harmonic smile.

Descriptors: Composite Resins; Esthetics, Dental; Dentistry, Operative; Tooth Bleaching.
\end{abstract}

\section{Resumen}

La valorización de aspectos que rigen los conceptos de estética en la sociedad torno cada vez más común la búsqueda por tratamientos estéticos y funcionales. El blanqueamiento dental asociado a restauraciones directas son alternativas eficientes para devolver la estética y función en un tiempo clínico menor y a un menor costo. Este caso clínico tiene por objetivo presentar la remodelación estética y cierre de diastemas en la región anterior de un paciente adulto joven, asociando técnicas de blanqueamiento dental y remodelación/restauración con resina compuesta. La metodología clínica desarrollada en este caso, devolvió eficazmente la función y estética a los dientes anteriores de la paciente, proporcionando una sonrisa más armónica.

Descriptores: Resinas compuestas. Estética dental. Operatoria dental. Blanqueamiento de Dientes.

\section{INTRODUÇÃO}

A aparência é um fator crucial na autoestima dos indivíduos e diversos são os motivos nos quais os pacientes procuram por procedimentos clínicos em odontologia, que primam pelo planejamento e obtenção de resultados estéticos favoráveis. A desarmonia do sorriso pode ser determinada pela assimetria e/ou desproporcionalidade entre um grupo de dentes e destes com as estruturas periodontais e orofaciais, como os lábios e face em geral. Aspectos relacionados às alterações de posição, forma, tamanho, cor e textura da face vestibular dos dentes anteriores podem comprometer a estética dental e harmonia facial $^{1,2}$.

Dentre as alterações de forma e tamanho dos dentes, os diastemas dentais são definidos como sendo o espaço entre os dentes ou a ausência de contato entre dois ou mais dentes consecutivos, geralmente encontrados na região anterior da maxila. Diversas são as etiologias, podendo ser atribuída à discrepância de tamanho dos dentes, à presença de freio com baixa inserção, à fusão imperfeita da linha média do osso maxilar, dentre outras ${ }^{2,3}$. Os padrões de estética e os conceitos de beleza e harmonia dental tem proporcionado um constante desenvolvimento em tecnologia, a fim de que os materiais dentários restauradores possam reproduzir de forma o mais fiel possível, às características da estrutura dental ${ }^{1}$. Os atuais sistemas de resinas compostas apresentam grande variedade de cores e translucidez, assim, a técnica de estratificação proporciona excelentes resultados estéticos, permitindo reproduzir as propriedades ópticas inerentes aos dentes naturais. Este material e a técnica restauradora direta apresentam-se como uma solução viável clinicamente para remodelar os dentes anteriores com alteração de forma e cor e até mesmo em dentes com problemas de alinhamento e posicionamento ${ }^{4}$.

Quanto aos dentes escurecidos, com etiologia relacionada a fatores extrínsecos ou intrínsecos, que geralmente causam desconforto estético, o clareamento 
dental é indicado como um tratamento primário no contexto dos procedimentos clínicos, que consiste basicamente na aplicação de um gel clareador a base de peróxido de carbamida ou de hidrogênio sobre os dentes que se pretende clarear. Este processo pode ser realizado em consultório ou pelo próprio paciente supervisionado pelo cirurgiãodentista $^{5-7}$. O caso em clínico tem por objetivo discorrer sobre a remodelação estética e o fechamento de diastema em dentes anteriores superiores de uma pessoa adulta jovem por meio do clareamento dental (técnica em consultório associado à técnica caseira supervisionada pelo dentista) e a finalização com resina composta.

\section{REVISÃO DE LITERATURA}

Realizou-se um estudo epidemiológico descritivo. O sorriso harmonioso é uma exigência estética importante no convívio em sociedade. Desta forma, qualquer alteração no padrão de normalidade da estrutura dentária implica diretamente na necessidade de correção. $\mathrm{O}$ anseio por um sorriso estético e harmônico eleva o nível de exigência dos pacientes, uma vez que se torna fator de relevância para sua aceitação na sociedade e autoestima. Dentes brancos, bem contornados e bem alinhados contribuem para o estabelecimento do padrão de beleza nos dias de hoje ${ }^{5}$.

A desarmonia estética do sorriso pode ocasionar perda de autoconfiança e autoestima. Pode até mesmo contribuir para o desenvolvimento de distúrbios psicológicos e comportamentais, levando o indivíduo a adotar um comportamento tímido, reservado e retraído ${ }^{8}$. Dentre as alterações relevantes na aparência estética, podemos citar o mau posicionamento dos dentes, seguido das alterações de cor e forma, e também a presença de diastemas entre os dentes ${ }^{2,9}$.

Sabe-se que a ortodontia geralmente é indicada no tratamento dos diastemas dentais, proporcionando melhor alinhamento dos dentes nos arcos dentários. Entretanto, quando os caninos se encontram alinhados em classe I e o principal problema é devido à uma mínima desproporção entre os dentes, pode-se optar pelo fechamento com resina composta pela técnica direta ou até os laminados cerâmicos minimamente invasivos ${ }^{10,11}$. O sucesso funcional e estético está diretamente relacionado a um planejamento correto determinado pelo cirurgião-dentista na visão multidisciplinar, e este deve ter pleno conhecimento da odontologia adesiva e dos materiais restauradores resinosos. Claramente é necessário observar e planejar o caso corretamente, avaliando os contatos oclusais existentes em máxima intercuspidação habitual, e nos movimentos excursivos de lateralidade e protrusão ${ }^{8}$.

Dentes vitais com frequência se apresentam em cor ou forma alterada, levando à insatisfação estética por parte do paciente. Além disso, manchas e/ou defeitos no esmalte podem também ocorrer por inúmeros fatores, incluindo hipoplasia, fluorose, pigmentação por medicamentos e desmineralização por cárie, entre outros ${ }^{7}$. Na tentativa de reestabelecer a estética, procedimentos como o clareamento dental, a microabrasão do esmalte, a confecção de facetas diretas ou indiretas e as restaurações diretas em resina composta podem ser adotados ${ }^{12}$.

Segundo a literatura, a remodelação estética em resina composta permite obter resoluções estéticas satisfatórias com tempo clínico curto e baixo custo. Para um sorriso esteticamente agradável, parâmetros como a composição facial e as características da morfologia dentária precisam estar harmônicos ${ }^{13,14}$. A abordagem clínica no tratamento deve ser sempre aquela mais conservadora possível e que assegure os requisitos estéticos básicos ${ }^{15}$

É importante ressaltar a inclusão de uma etapa fundamental no planejamento, que é o enceramento diagnóstico, o qual permite maior previsibilidade no resultado clínico além de redefinir a morfologia dentária individualmente para cada paciente e executar um ensaio restaurador com menor chance de erros ${ }^{5,16}$

Como parte do tratamento o uso dos agentes clareadores previamente à técnica restauradora direta com as resinas compostas é um recurso a ser utilizado para minimizar o efeito do fundo escuro na aparência final das restaurações em dentes com manchamento intrínseco severo. O clareamento dental é uma alternativa simples de tratamento conservador para dentes com alteração de cor e que garante resultados satisfatórios ${ }^{5,7}$. Pois é importante o profissional ter um completo entendimento dos conceitos de cor e do comportamento óptico do material restaurador e da estrutura dentária para reproduzir uma restauração que alcance com sucesso os requisitos estéticos. A expressão cromática dos dentes é variável e dependem da interação entre o esmalte, a dentina e a polpa, com fenômenos de reflexão e refração da luz ${ }^{17}$.

Por fim outro grande desafio clínico é obter contorno, forma, textura da superfície e mimetização da estrutura dentária, principalmente em pacientes jovens, devido à grande quantidade de detalhes anatômicos ${ }^{18,29}$. O esmalte nestes casos é mais branco, com alta opalescência e baixa translucidez; a dentina apresenta-se em formato de lóbulos bem desenvolvidos e evidentes. A borda incisal com alta translucidez e o encontro do esmalte palatal com o vestibular forma um fino halo opalescente, mais branco. A curvatura vestibular é mais pronunciada, dando maior suporte ao lábio ${ }^{4,20}$

\section{CASO CLÍNICO}

Paciente de 19 anos, sexo feminino, compareceu à Clínica de Atenção Integral ao Adulto I da Faculdade de Odontologia da Universidade Federal de Minas Gerais, queixando-se da estética do seu sorriso devido à coloração amarelada e a forma dos dentes anteriores. (Figura 1). Ao exame clinico e radiográfico, observou-se que a paciente apresentava saúde bucal e periodontal satisfatórias, no entanto notou-se a presença de diastema mesial entre dos dentes 11 e 21 (Figura 2).

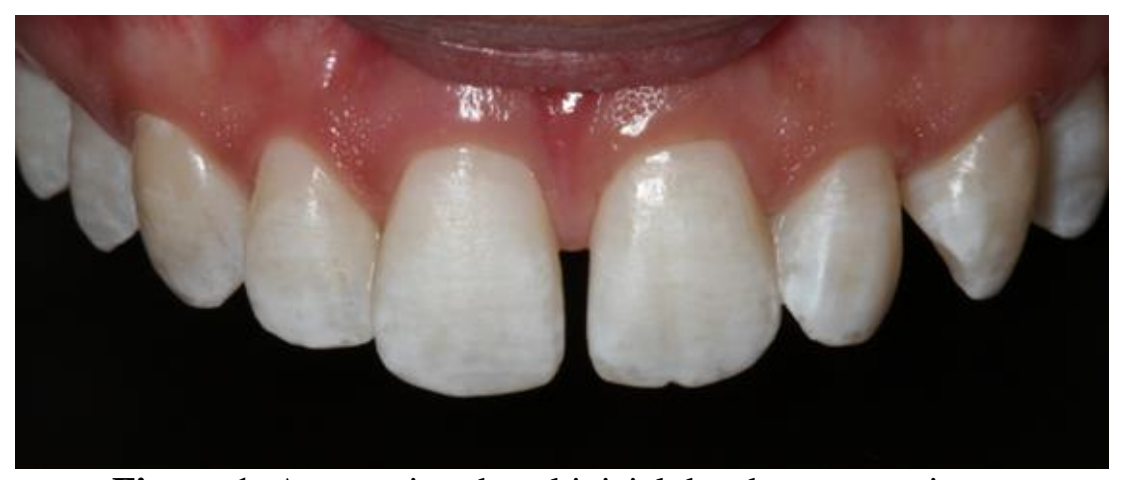

Figura 1: Aspecto intrabucal inicial dos dentes superiores.

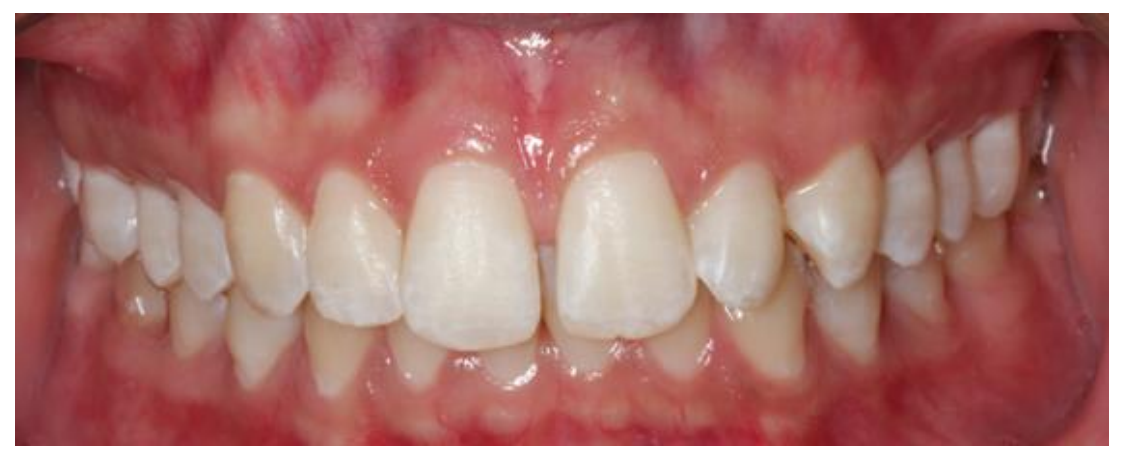

Figura 2: Aspecto intrabucal inicial com dentes em oclusão. 
Procedeu-se então às moldagens do arco superior e inferior com hidrocolóide irreversível (Alginato, Jeltrate, Dentsply, Brasil) para a obtenção de modelos de estudo em gesso especial (tipo IV, Durone, Dentsply, Brasil). O plano de tratamento foi guiado pelos modelos de estudo para a realização do enceramento diagnóstico (Figura 3), visando a harmonia estética dos dentes anteriores superiores e permitindo a confecção de guias em silicone para posterior ensaio restaurador (mock-up), e orientação da técnica restauradora direta com resina composta.

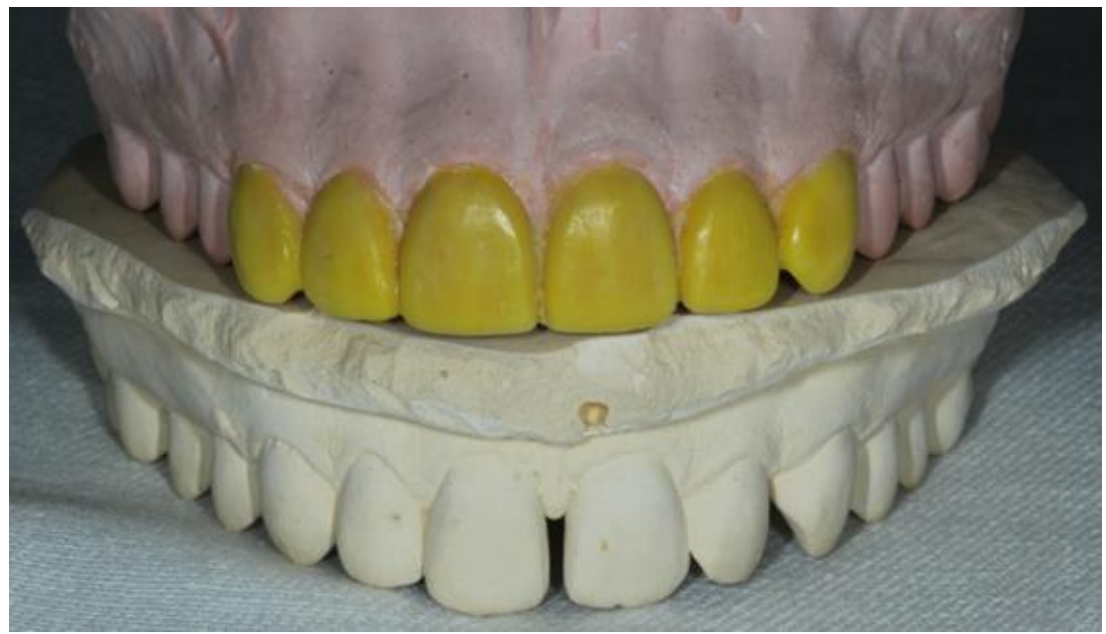

Figura 3: Modelo de estudo inicial e modelo de estudo com o enceramento diagnóstico.

O tratamento foi iniciado com o clareamento dentário utilizando-se a técnica de consultório com gel de peróxido de hidrogênio a 38\% (Opalescence Xtra Boost, Ultradent, EUA). Inicialmente foi realizada a profilaxia dos dentes com taça de borracha e pedra pomes, análise inicial da cor dos dentes e registro fotográfico. Procedeu-se ao isolamento do campo operatório com a barreira gengival fotoativada (Opaldam, Ultradent, EUA) e um afastador bucal (Arcflex, FGM, Brasil). Ao término do clareamento em consultório, o paciente foi orientado a utilizar um gel de peróxido de carbamida a 15\% (Opalescence PF, Ultradent, USA) com auxílio de moldeiras em silicone, diariamente, sendo duas horas pela manhã e duas horas à noite, num período de 30 dias. O acompanhamento da evolução do clareamento foi observado a cada sete dias, totalizando um mês de clareamento (Figuras 4 e 5).

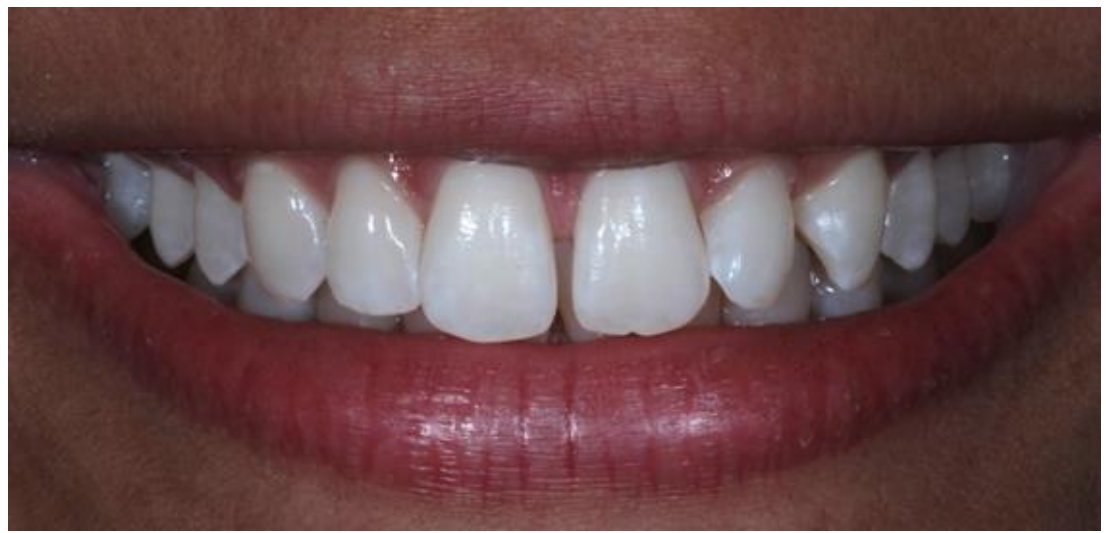

Figura 4: Sorriso da paciente após o clareamento dental.

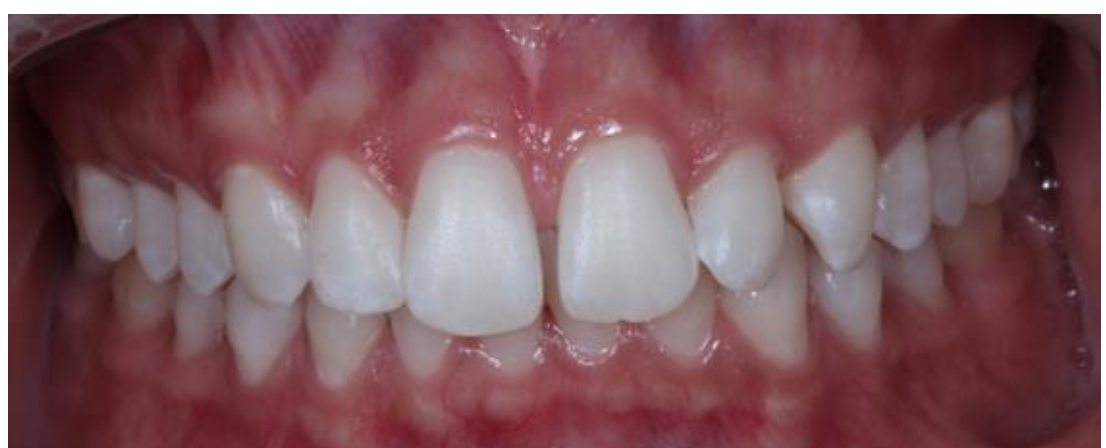

Figura 5: Aspecto intrabucal dos dentes em oclusão após o clareamento dental.
Ao final do clareamento, procedeu-se ao polimento dos dentes e aplicação tópica de flúor neutro e incolor e a verificação da alteração no croma dos dentes.

Findado o tratamento clareador, procedeu-se ao tratamento restaurador com resina composta pela técnica direta. Com auxílio dos modelos de estudo já com o enceramento diagnóstico, foram confeccionados dois guias em silicone polimerizado por condensação (Clonage, DFL, Brasil). Com o primeiro guia de silicone, foi realizado um ensaio restaurador ou "Mock-up" com resina bisacrílica (Structur 3, Voco, Alemanha) para que o paciente pudesse observar o resultado final do tratamento. (Figura 6).

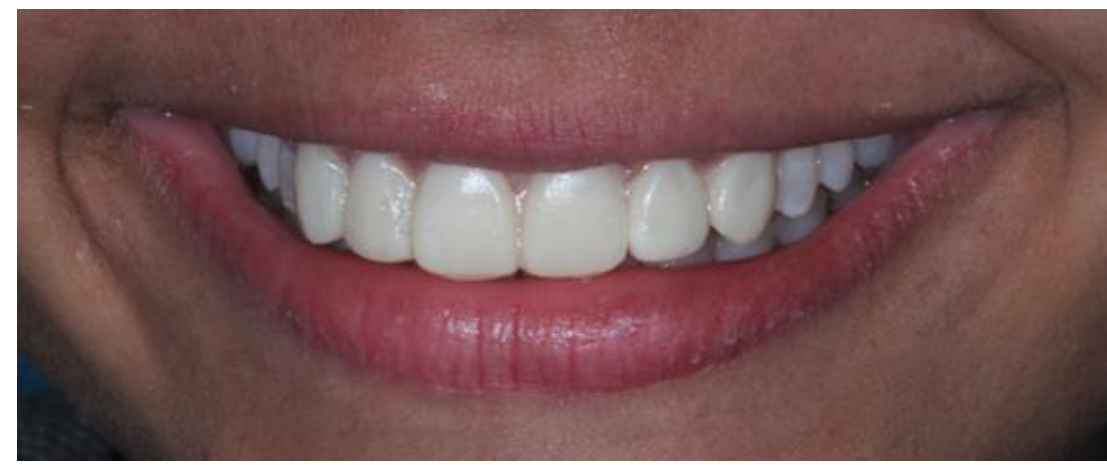

Figura 6: Sorriso da paciente após realização do ensaio clínico mock-up.

Na sequência com a aprovação do paciente, iniciouse o procedimento restaurador com auxílio do segundo guia em silicone para a reprodução da face palatina dos dentes anteriores (Figura 7). Procedeu-se ao isolamento do campo operatório e ameloplastia dos dentes 22 e 23 com ponta diamantada 2135. Realizou-se a profilaxia dos dentes com pedra pomes e água, condicionou-se o esmalte dental com ácido fosfórico $37 \%$ (Ultradent, EUA) por 30 segundos e lavou-se com água durante 60 segundos, secou-se o esmalte até obter o aspecto de giz (Figura 8). O sistema adesivo (PK1, Ultradent, EUA) foi aplicado e fotoativado por 20 segundos.

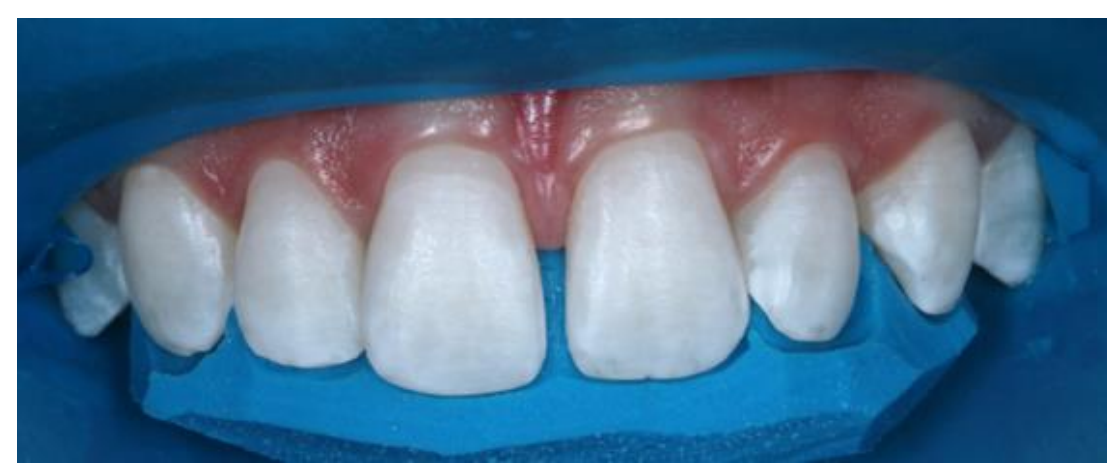

Figura 7: Guia de silicone adaptado à palatina dos dentes anteriores sob isolamento absoluto "modificado".

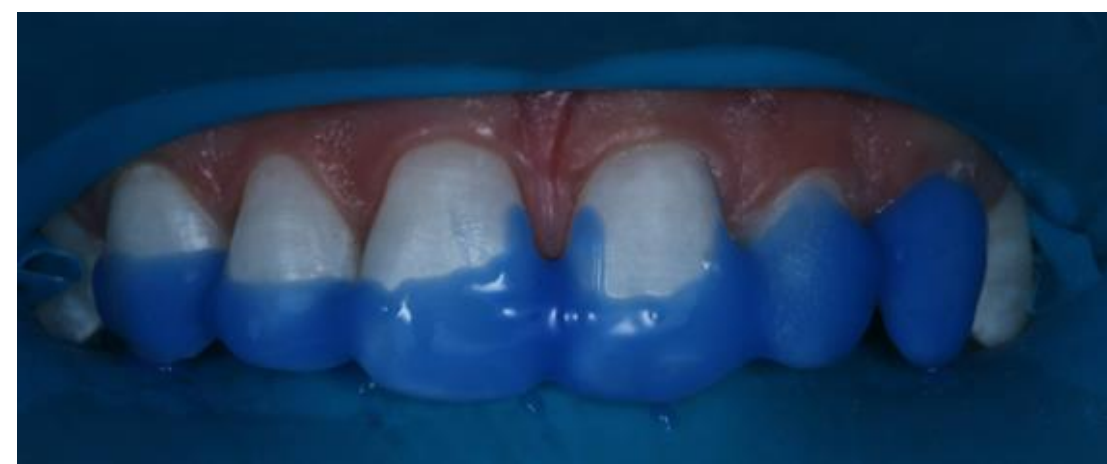

Figura 8: Condicionamento ácido realizado na face vestibular dos dentes anteriores sob isolamento absoluto "modificado".

Iniciou-se a inserção da resina composta na cor TM (Trans Mist) (Vitalescence, Ultradent, EUA), relativa ao esmalte palatino, com auxílio do segundo guia de silicone e estas porções foram fotoativadas com a guia em posição por 10 segundos e após a remoção da mesma, por mais 20 
segundos em cada dente (Figura 9). Uma vez restaurado o esmalte palatino, procedeu-se a aplicação de uma resina de maior opacidade, B1 dentina (Vitalescence, Ultradent, EUA) para reproduzir a forma e o conteúdo dentinário (Figura 10). Em seguida, inseriram-se porções de resina composta relativa ao esmalte na cor PF (Pearl Frost) (Vitalescence, Ultradent, EUA) reproduzindo a forma dental conforme o enceramento diagnóstico (Figura 11).

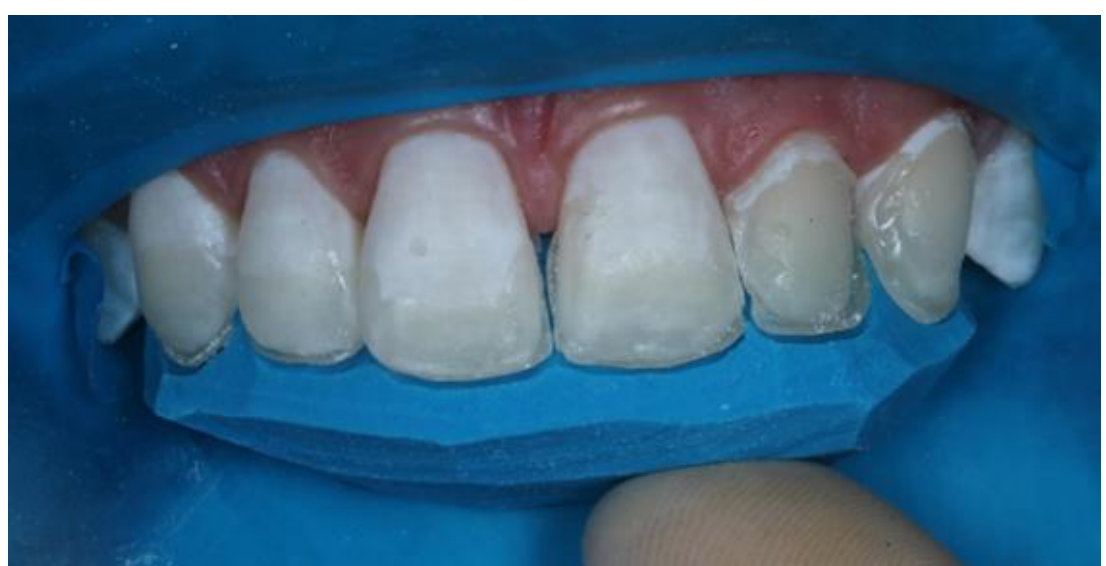

Figura 9: Aspecto dos dentes anteriores após a inserção da resina composta na cor TM relativa ao esmalte palatino.

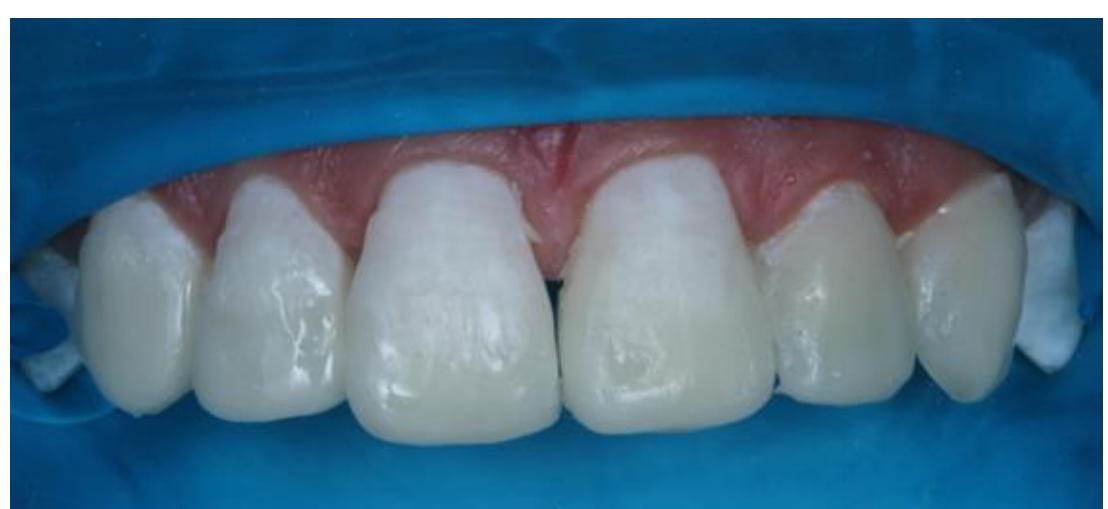

Figura 10: Aspecto dos dentes anteriores após a inserção da resina composta na cor $\mathrm{B} 1$ relativa à dentina.

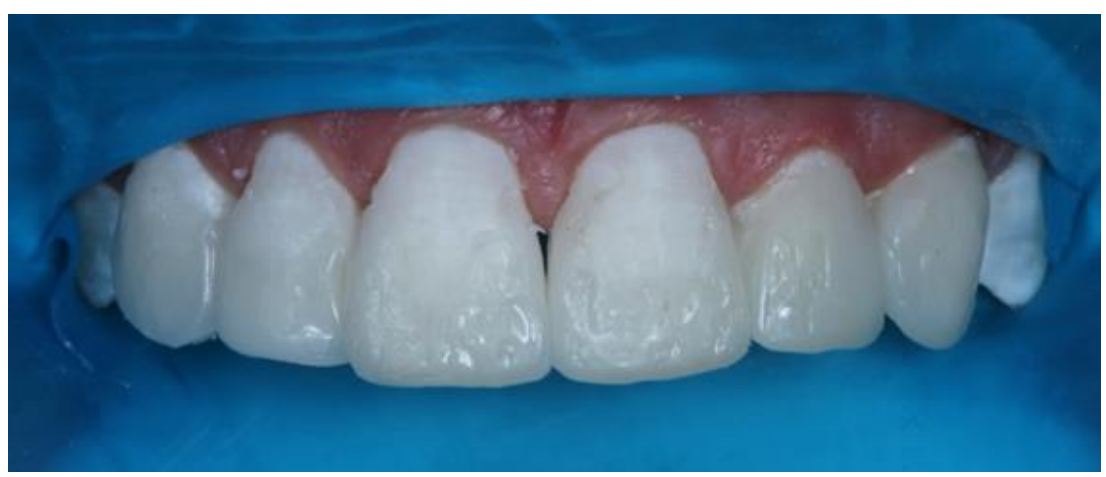

Figura 11: Aspecto dos dentes anteriores após a finalização da camada de resina comporta na cor PF do esmalte.

Imediatamente após o procedimento restaurador, realizou-se à remoção dos excessos grosseiros com lâmina de bisturi \# 12 e pontas diamantadas FF em alta rotação. A seguir, procedeu-se com o acabamento inicial em baixa rotação com pontas de borracha abrasivas (Sistema Jiffy, Ultradent, EUA). Após a checagem dos contatos oclusais e as guias de desoclusão, verificou-se o êxito obtido no tratamento (Figuras 12 a 14).

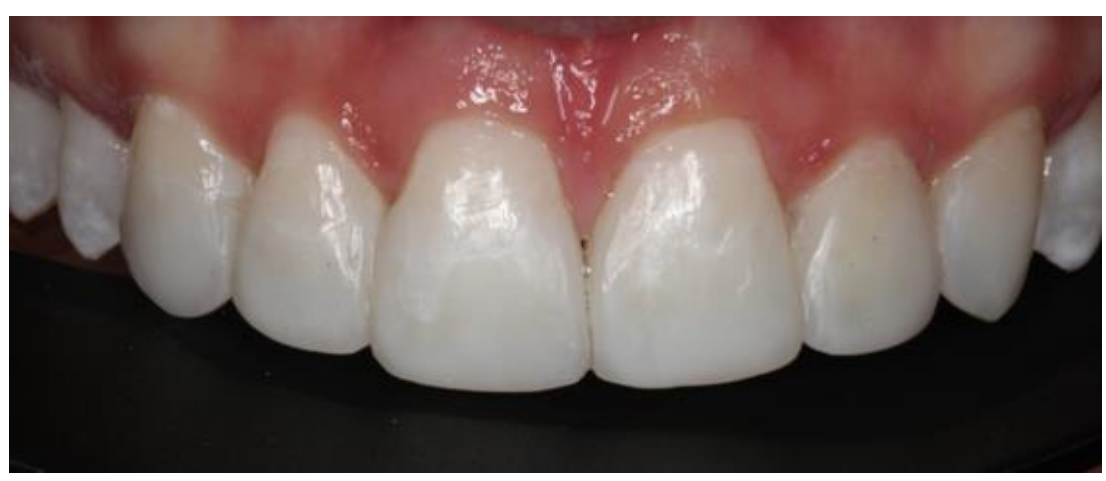

Figura 12: Aspecto intrabucal final dos dentes superiores.

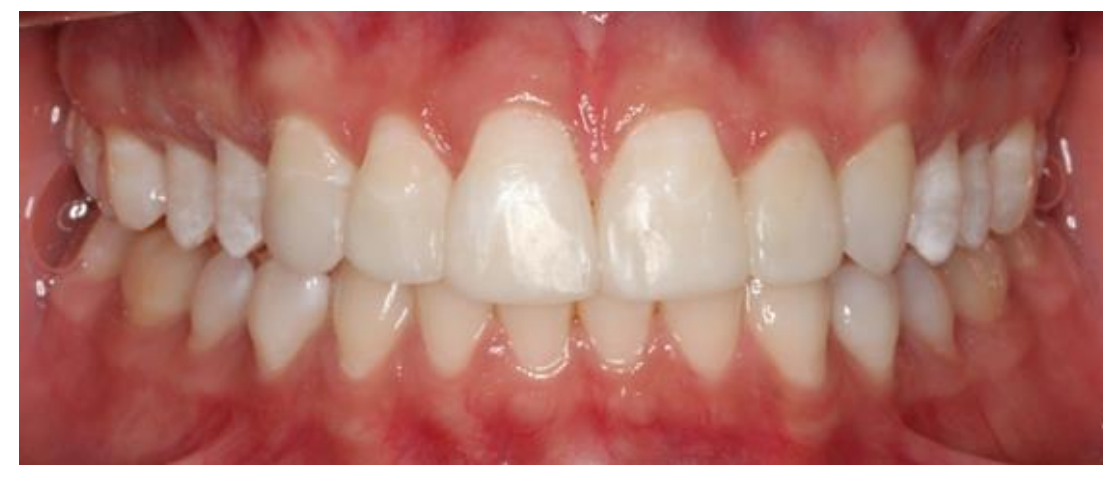

Figura 13: Aspecto intrabucal dos dentes em oclusão após a finalização do tratamento.

Decorridos sete dias, realizou-se o polimento com escovas de carbeto de silício (Jiffy Brush, Ultradent, USA) e pastas de polimento de granulação 1 e 0,5 micrômetros aplicadas com um disco de feltro (Ultradent, EUA).

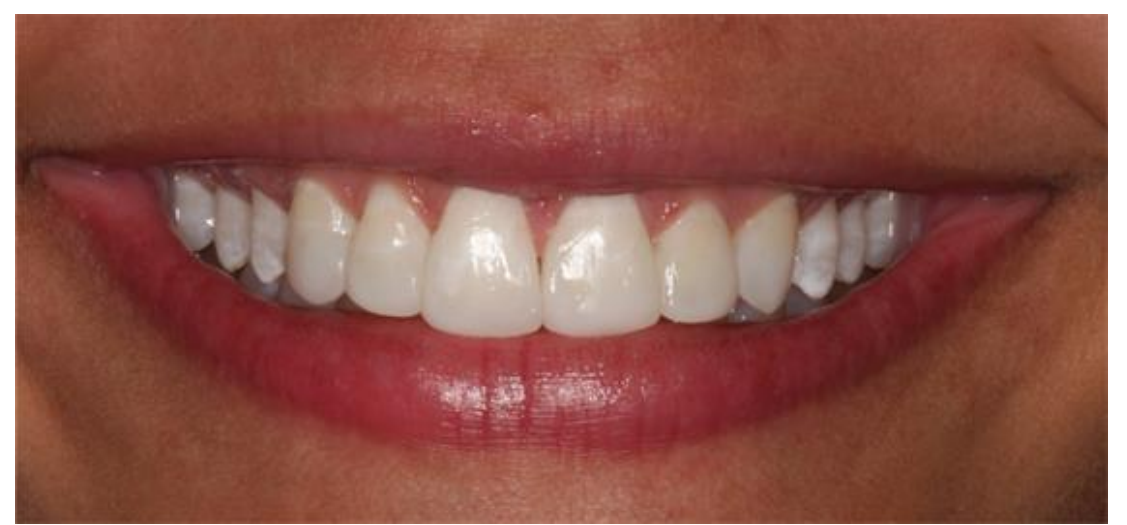

Figura 14: Sorriso da paciente após a finalização do tratamento.

\section{DISCUSSÃO}

As restaurações diretas em resina composta apresentam-se como uma opção clínica de tratamento em casos de diastemas ou anomalias na forma dentária. ${ }^{4} \mathrm{~A}$ associação com o clareamento dental previamente ao procedimento restaurador possibilita um resultado mais favorável, uma vez que aumenta o valor e o brilho do esmalte dental acentuando as características de translucidez, o que foi observado no resultado final deste trabalho ${ }^{20,21}$. O planejamento clínico neste relato de caso clínico foi direcionado para obtermos melhores características de cor, opacidade, translucidez e opalescência aos dentes do paciente com técnicas minimamente invasivas.

Além disso, o enceramento diagnóstico é outra etapa fundamental do tratamento, pois permite a análise individualizada do caso conferindo maior previsibilidade do resultado clínico ${ }^{16,22}$. Com um ensaio restaurador em resina bisacrílica, o paciente tem a possibilidade de visualizar o resultado final e junto ao cirurgião-dentista, definir previamente a forma, a posição e a proporção das futuras restaurações ${ }^{5}$, o que foi possível obter neste trabalho. Esta etapa do tratamento possibilita ao profissional e ao paciente verificar os anseios funcionais e estéticos e ratificá-los ou aperfeiçoá-los.

O clareamento dental é um potencializador do tratamento restaurador estético, é uma técnica simples e eficaz que garante um excelente resultado estético. ${ }^{23} \mathrm{O}$ prognóstico favorável é dependente de um diagnóstico correto e um plano de tratamento adequado, por isso, é necessário uma avaliação minuciosa antes da indicação e eleição da técnica clareadora a ser utilizada. O tratamento deve ser realizado e sempre supervisionado pelo cirurgiãodentista, o qual deve estabelecer o tempo de tratamento, observando o ponto de saturação do esmalte ${ }^{23-25}$. Neste trabalho, optou-se pelo clareamento dental associando-se as técnicas em consultório e caseira, com excelente resultado clínico sem intercorrências para o paciente e sem 
sensibilidade trans e pós-operatória. A associação das técnicas de clareamento dental é uma alternativa muito utilizada nos casos em que deseja um resultado mais rápido e eficaz, incentivando o paciente já que permite um resultado clínico logo na primeira semana ${ }^{24,25}$. Além disso, possibilita um resultado estético mais duradouro quando comparado à utilização somente da técnica em consultório ${ }^{7,25-26}$

Outra possibilidade de tratamento restaurador estético são as restaurações indiretas em cerâmicas com as facetas ou as lentes de contato. Porém, a técnica direta em resina composta apresenta algumas vantagens: é executada em menor tempo clínico, podendo ser realizadas em uma única sessão. Ademais é uma técnica mais conservadora, exigindo mínimo ou nenhum desgaste de estrutura sadia, possuindo custo mais baixo ${ }^{24,26}$. Neste trabalho optou-se pelas restaurações em resina composta pela técnica direta em detrimento da técnica indireta com as facetas devido a possibilidade de executar um tratamento mais simples, com menor tempo clínico e baixo custo.

O correto acabamento e polimento das restaurações diretas em resina composta são essenciais para garantir um menor manchamento, baixo acúmulo de biofilme e melhor resistência ao desgaste e integridade marginal. Quando executado de forma correta proporciona a obtenção de uma restauração que reproduza em detalhes a forma e a textura dos dentes e garanta uma maior longevidade de cor e brilho ${ }^{4,27,29}$. Neste trabalho, realizou-se um protocolo criterioso de acabamento e polimento com borrachas abrasivas em diferentes granulações seguido de uma escova de borracha impregnada com carbeto de silício e posteriormente duas pastas diamantadas de polimento com granulações diferentes de 1 e 0,5 micrometros com o objetivo de obtermos uma superfície lisa e com alto brilho. O acompanhamento e a manutenção do tratamento com sessões de acabamento e polimento das restaurações a cada ano poderão garantir maior longevidade ao tratamento realizado.

A associação de técnicas no clareamento dental possibilita ao profissional obter resultados clínicos com maior segurança e longevidade no tratamento. A finalização do tratamento estético com a remodelação estética dos dentes anteriores superiores com resina composta pela técnica direta apresenta-se com uma alternativa simples e eficaz que pode ser aplicada pelos profissionais clínicos e especialistas com previsibilidade e um prognóstico favorável quando utilizamos os modelos de estudo e o enceramento diagnóstico. Ademais, estas técnicas devem ser divulgadas e compartilhadas com os profissionais.

\section{CONCLUSÃO}

O clareamento dental reduziu o croma e aumentou o valor dos dentes proporcionando a potencialização do resultado estético obtido com as resinas compostas. As restaurações diretas em resina composta são uma excelente opção clínica para a remodelação estética dos dentes anteriores superiores, pois garantem resultado esteticamente favorável em tempo clínico curto.

\section{REFERÊNCIAS}

1. Alves LMM, Goyatá FR, Izolani Neto O. Resina composta em dentes anteriores com hipoplasia do esmalte. Clín int j braz dent. 2013; 9(1):58-64.

2. Kina M, Leal FA, Fabre AF, Martin OCL, Coimbra MC. Tratamento restaurador estético minimamente invasivo através da técnica direta com compósito. Relato de caso clínico. Arch Health Invest. 2015; 4(4):50-5

3. Zuben PHV. Diastema: conceito, etiologia, diagnóstico, opções de tratamento [trabalho de conclusão de curso] Piracicaba: Faculdade de Odontologia de Piracicaba, Unicamp; 2004.

4. Sene F, Kasuya AVB. Esthetic remodeling of maxillary incisors with composite resin: color, shape and proportion correction. J Clin Dent Res. 2016; 13(2):70-7.

5. Alves NV, Santana TAT, Landim EVF, Tavares GR. Reabilitação estética e funcional do sorriso: revisão de literatura. Revista Interfaces. 2015; 3(9):25-30.

6. Scarpelli AC, Bendo CB, Novaes-Júnior JB, Barreiros ID, Paiva SM. Aesthetic management of tooth discolouration: conservative treatment for a patient with undifferentiated nasopharyngeal carcinoma. Rev odonto ciênc. 2011; 26(1):84-7.

7. Zanín F, Freitas PM, Aranha ACC, Ramos TM, Lopes AO. Clareamento de dentes vitais. Rev Assoc Paul Cir Dent. 2010; 64(5):338-45.

8. Keene HJ. Distribution of diastemas in the dentition of a man. Am J Phys Antropol. 1963; 21(4):437-41.

9. Fontana UF, Pacheco IB. Contorno cosmético. Rev Ibero Americana Odontol Est Dent. 2004; 3(9):33-9.

10. Berwanger C, Denadai GA, Yamith A, Ev LD, Rodrigues RB, Coelho-de-Souza FH et al. Fechamento de diastema com resina composta direta-relato de caso clínico. Rev Assoc Paul Cir Dent. 2016; 70(3):317-22.

11. Simões MP, Albino LGB, Reis AF, Rodrigues JA. Restaurações estéticas conservadoras em dentes anteriores. Rev dent press estética. 2009; 6(1):90-101.

12. Aranha ACC, Mitsui FHO, Marchi GM. Facetas diretas em resina composta pós-microabrasão-Relato de caso clínico. J Bras Dent Estet. 2003; 2(5):72-8.

13. Pascotto RC, Boselli GL, Nunes MCP. Considerações sobre o planejamento e confecção de facetas diretas em resina composta. Rev dent press estética. 2008; 5(2):96-109.

14. Boseli G, Pascotto RC. Incisivos laterais conóides: diagnóstico, planejamento e tratamento restaurador direto. Rev dent press estética. 2007; 4(2):89-96.

15. Goettems ML, Azevedo MS, Torriani DD, Romano AR, Baldissera R, Demarco FF. Direct composite veneer to treat primary teeth with sequela of dental trauma: a case report. RFO. 2011; 16(3):327-31.

16. Calixto LR, Bandeca MC, Andrade MD. Enceramento diagnóstico: previsibilidade no tratamento estético indireto. Rev dent press estética. 2011; 8(4):26-37.

17. Baratieri LN, Araujo E, Monteiro S Jr. Color in natural teeth and direct resin composite restorations: essential aspects. Eur J Esthet Dent. 2007; 2(2):172-86.

18. Wittmann K, Giacomelli Neto R, Longo RE, Sene F. Restauração estética do sorriso por meio da integração de técnicas de clareamento e restauração direta de resina composta. Clín int j braz dent. 2013; 9(4):456-67.

19. Campos PRB, Amaral D, Silva MAC, Barreto SC, Pereira GDS, Prado M. Reabilitação da estética na recuperação da harmonia do sorriso: relato de caso. RFO. 2015; 20(2):227-31.

20. Carvalho NR, Brasil CMV, Mota CCBO, Teixeira HM, Beatrice LCS, Nascimento ABL. Clareamento caseiro supervisionado: revisão de literatura. Clín int j braz dent. 2008; 7(3):178-83.

21. Aguiar HC, Rodrigues CRT, Goyatá FR, Izolani Neto $\mathrm{O}$, Landa FV. Remodelação estética em dentes 
anteriores: relato de caso clínico. Clín int j braz dent. 2013; 9(4):396-402.

22. Seymour DW, Patel M, Chan MFWY. Aesthetic preview: a novel approach. Dent Update. 2012; 39(6):422-6

23. Baratieri LN, Monteiro Jr S, Andrada MAC, Vieira LCC. Clareamento dental. São Paulo: Santos, 1994.

24. Haywood VB, Heymann HO. Nightguard vital bleaching. Quintessence Int. 1989; 20(3):173-6.

25. Figueiredo JLG, Niedemaier KC, Zaia WLS. Clareamento dental: relato de caso clínico avaliado pela análise espectrofotométrica. Rev dent press estética. 2007; 4(4):92-100.

26. Goyatá FR, Gilson JGR, Bello RF. Clareamento em dentes vitais: associação de técnicas - relato de caso clínico. Dent Sci. 2011; 5(13): 29-36.

27. Wirsching E, Contemporary options for restoration of anterior teeth with composite. Quintessence Int. 2015; 46(6):457-63.

28. LeSage BP. Aesthetic anterior composite restorations: a guide to direct placement. Dent Clin North Am. 2007; 51(2):359-78

29. Pimentel PEZ, Goyatá FR, Cunha LG. Influência da técnica de polimento na lisura superficial de resinas compostas. Clín int j braz dent. 2012; 8(2):226-34.

\section{CONFLITO DE INTERESSES}

Os autores declaram não haver conflitos de interesse.

\section{AUTOR PARA CORRESPONDÊNCIA}

\section{Amália Moreno}

amalia_moreno@yahoo.com.br

Submetido em 04/07/2017

Aceito em 10/08/2017 